\title{
Distribution, ecological risk assessment and source identification of pollutants in soils of different land-use types in degraded wetlands
}

\author{
Yangyang Han ${ }^{\text {Equal first author, 1, 2, }}$, Hongjie Wang Equal first author, 1, 2, ${ }^{3}$, Guangming Zhang ${ }^{4}$, Shengqi Zhang ${ }^{1,2,3}$, Xingchun Liu ${ }^{1,2}$ \\ 3 , Ling Liu Corresp. 1, 2, 3 \\ ${ }^{1}$ School of Eco-Environment, Hebei University, Baoding 071002, China \\ 2 Institute of Life Science and Green Development, Hebei University, Baoding 071002, China \\ 3 Hebei Key Laboratory of Close-to-Nature Restoration Technology of Wetlands, Hebei University, Baoding 071002, China \\ 4 School of Energy and Environmental Engineering, Hebei University of Technology, Tianjin 300130, China \\ Corresponding Author: Ling Liu \\ Email address: liuling@hbu.edu.cn
}

Background. Urbanization and global warming are generating ecological degradation and land pattern alteration problems in natural wetlands. These changes are greatly affecting the ecological services of wetlands. Therefore, there is an urgent need to explore the relationship between pollutants and land-use type for wetland restoration purposes. Zaozhadian Lake is a freshwater wetland in the North China Plain, which is facing degradation and land-use types changes. An experiment for analyzing soil pollutants was conducted in three land-use types of farmland, lake, and ditch in the Zaozhadian Lake. The aims of this study were to identify the distribution, pollution degree, and sources of pollutants in different land-use types, and to explore the influence of land-use type changes on contamination. Methods. In this study, surface sediments $(0-10 \mathrm{~cm})$ of three land types (farmland, lake, and ditch) in Zaozhadian Lake were collected, and heavy metals ( $\mathrm{Cu}, \mathrm{Ni}, \mathrm{Zn}, \mathrm{Pb}, \mathrm{Cd}, \mathrm{Cr}, \mathrm{Hg}$ ), As, total nitrogen (TN), total phosphorus (TP) and organic matter $(\mathrm{OM})$ were determined. Kriging interpolation was used to visualize the pollutants distribution. The pollution degree of TN and TP was evaluated by the Nemerow pollution index. The pollution of heavy metals and As was evaluated by the geological accumulation index $\left(I_{\text {geo }}\right)$ and the potential ecological risk index $(R I)$. Then, Dual hierarchical clustering analysis and the principal component analysis were performed to further analyze the impact of land type changes on pollutants. Results. The heavy metal contents in the farmland were higher than other areas, while the TN $\left(3.71 \pm 1.03 \mathrm{~g} \cdot \mathrm{kg}^{-1}\right)$ and OM $\left(57.17 \pm 15.16 \mathrm{~g} \mathrm{~kg}^{-1}\right)$ in lake sediments were higher than that in other regions. Farmland, lake, and ditches had low ecological risks, with $R /$ values of $84.21,71.34$, and 50.78 , respectively. The primary heavy metal pollutants are $\mathrm{Pb}, \mathrm{Cu}$, and $\mathrm{Ni}$. Furthermore, 
$\mathrm{Cu}, \mathrm{As}, \mathrm{Ni}, \mathrm{Pb}$, and $\mathrm{Zn}$ were primarily derived from agriculture pollution, the source of $\mathrm{Cd}$ was the industrial pollution, and $\mathrm{Cr}$ mainly originated from natural sources. Nutrients primarily came from the decomposition of aquatic animals, plants, and human-related activities. When the lake area was converted into farmland, the heavy metal concentrations in the soils increased and the TN and OM decreased. Based on the results, this study put forward key strategies including the adjustment of the land-use type and restriction of the entry of pollutants into the wetland ecosystems in the Zaozhadian Lake. More attention should be paid to the impact of land-use type change on pollutants in wetlands. 


\section{Distribution, ecological risk assessment and source} 2 identification of pollutants in soils of different land3 use types in degraded wetlands

6 Yangyang Han ${ }^{1,2,3,}$ \&, Hongjie Wang ${ }^{1,2,3, ~ \&, ~ G u a n g m i n g ~ Z h a n g ~}{ }^{4}$, Shengqi Zhang ${ }^{1,2,3}$, Xingchun 7 Liu ${ }^{1,2,3}$, Ling Liu ${ }^{1,2,3}$

8

$9 \quad{ }^{1}$ School of Eco-Environment, Hebei University, Baoding 071002, China

$10{ }^{2}$ Institute of Life Science and Green Development, Hebei University, Baoding 071002, China

$11{ }^{3}$ Hebei Key Laboratory of Close-to-Nature Restoration Technology of Wetlands, Hebei

12 University, Baoding 071002, China

$13{ }^{4}$ School of Energy and Environmental Engineering, Hebei University of Technology, Tianjin 14 300130, China

\& Yangyang Han and Hongjie Wang contribute equally to the article.

17 Corresponding Author:

18 Ling Liu $1,2,3$

19 Wusi East Road, Baoding, Hebei, 071000, China

20 Email address: liuling@hbu.edu.cn 


\section{Abstract}

22 Background. Urbanization and global warming are generating ecological degradation and land

23

24

25

26

27

28

29

30

31

32

33

34

35

36

37

38

39

40

41

42

43

44

45

46

47

48

49

50

51

52

53

54

55

56

57

58

59

60

pattern alteration problems in natural wetlands. These changes are greatly affecting the ecological services of wetlands. Therefore, there is an urgent need to explore the relationship between pollutants and land-use type for wetland restoration purposes. Zaozhadian Lake is a freshwater wetland in the North China Plain, which is facing degradation and land-use types changes. An experiment for analyzing soil pollutants was conducted in three land-use types of farmland, lake, and ditch in the Zaozhadian Lake. The aims of this study were to identify the distribution, pollution degree, and sources of pollutants in different land-use types, and to explore the influence of land-use type changes on contamination.

Methods. In this study, surface sediments $(0-10 \mathrm{~cm})$ of three land types (farmland, lake, and ditch) in Zaozhadian Lake were collected, and heavy metals ( $\mathrm{Cu}, \mathrm{Ni}, \mathrm{Zn}, \mathrm{Pb}, \mathrm{Cd}, \mathrm{Cr}, \mathrm{Hg}), \mathrm{As}$, total nitrogen (TN), total phosphorus (TP) and organic matter (OM) were determined. Kriging interpolation was used to visualize the pollutants distribution. The pollution degree of TN and TP was evaluated by the Nemerow pollution index. The pollution of heavy metals and As was evaluated by the geological accumulation index $\left(I_{g e o}\right)$ and the potential ecological risk index ( $R I$ ). Then, Dual hierarchical clustering analysis and the principal component analysis were performed to further analyze the impact of land type changes on pollutants.

Results. The heavy metal contents in the farmland were higher than other areas, while the TN $\left(3.71 \pm 1.03 \mathrm{~g} \cdot \mathrm{kg}^{-1}\right)$ and $\mathrm{OM}\left(57.17 \pm 15.16 \mathrm{~g} \cdot \mathrm{kg}^{-1}\right)$ in lake sediments were higher than that in other regions. Farmland, lake, and ditches had low ecological risks, with $R I$ values of 84.21, 71.34, and 50.78 , respectively. The primary heavy metal pollutants are $\mathrm{Pb}, \mathrm{Cu}$, and Ni. Furthermore, $\mathrm{Cu}$, $\mathrm{As}, \mathrm{Ni}, \mathrm{Pb}$, and $\mathrm{Zn}$ were primarily derived from agriculture pollution, the source of $\mathrm{Cd}$ was the industrial pollution, and $\mathrm{Cr}$ mainly originated from natural sources. Nutrients primarily came from the decomposition of aquatic animals, plants, and human-related activities. When the lake area was converted into farmland, the heavy metal concentrations in the soils increased and the $\mathrm{TN}$ and $\mathrm{OM}$ decreased. Based on the results, this study put forward key strategies including the adjustment of the land-use type and restriction of the entry of pollutants into the wetland ecosystems in the Zaozhadian Lake. More attention should be paid to the impact of land-use type change on pollutants in wetlands.

\section{Introduction}

Wetlands play an important role in improving water quality, protecting biodiversity, and regulating climate (Acharya, Maraseni \& Cockfield, 2019). However, heavy metal-like pollutants are continuously flowing into wetlands, along with the global warming events, the destruction of wetlands by humans, and the continuous development of all types of industrial activities ( $L u$ et al., 2020). The flowing of pollutants into the wetlands can be affected by hydrodynamic forces, aquatic plants, microorganisms, and other physicochemical factors. These pollutants can be then retained in the soil or accumulated in the plants by precipitation and adsorption (Jiang et al., 2017). Excessive pollutants in wetlands can pose potential hazards to natural ecosystems, plants, human health, and other living organisms (Alahabadi \& Malvandi,

Peer] reviewing PDF | (2021:09:65482:2:0:NEW 13 Jan 2022) 
61

62

63

64

65

66

67

68

69

70

71

72

73

74

75

76

77

78

79

80

81

82

83

84

85

86

87

88

89

90

91

92

93

94

95

96

97

98

99

100

2018). In the past few decades, researchers have conducted numerous studies on soil pollution in wetlands ( $\mathrm{J}$ i et al., 2019a; Lu et al., 2018). Heavy metal contamination has gained wide attention for its toxicity, persistency, and non-biodegradability in the environment (Puthusseri et al., 2021). In addition, nitrogen and phosphorus has been a major concern because they are the key limiting nutrients for eutrophication in most aquatic ecosystems (Conley et al., 2009).

Recently, the interest in the effects of land pattern conversion on pollutant behavior in soil has increased (Bai et al., 2010). According to the Ramsar Convention on Wetlands $(R C W, 2018)$, about $35 \%$ of the natural wetlands have been lost since 1970 due to urbanization events (Hu et al., 2017). In fact, degraded wetlands are often used as agricultural land, and in industrial and urbanization constructions (Ding et al., 2020). Many studies have proved that contaminant accumulation can be inextricably linked to land use patterns (Tian et al., 2019; Sun et al., 2019), and land use conversion can directly or indirectly influence the geochemical position of contaminants (Jiao et al., 2014). For instance, Zheng et al. (2016) proved that there are fewer heavy metals in the forests of the Yangtze River Estuary compared to the heavy metals present in farmland areas. In addition, Bai et al. (2010) showed that there are differences in the distribution of soil pollutants of wetlands, conventional farmlands, and abandoned farmlands in Yilong lake. Other studies analyzed the pollution risk based on land use patterns, such as industrial areas ( $L u$ et al., 2018), lakes (Ji et al., 2019a), and agricultural lands (Wang et al., 2019). However, few studies have focused on the effects of land-use type conversion on heavy metals and nutrients, especially in wetlands. As the population continues to grow and develop, the wetland land patterns are gradually changing (Liu et al., 2020). Therefore, there is a need to analyze the influence of land-use type on contaminants in wetland soils. These finding can provide reference materials in targeted thinking related to sustainable development of wetland.

The Zaozhadian Lake is a comprehensive wetland composed of lake, rivers, and cultivated land, and it has significant characteristics of land-use type change. The studies on the Zaozhadian Lake focus mainly on aspects such as activities of microbial communities (Sun et al., 2021), contaminant contents (Wang et al., 2020), eutrophication (Pu et al., 2017), and ecological risk assessment ( $\mathrm{J}$ i et al., 2019b). However, these studies did not differentiate contamination based on land-use types. The objectives of this study were to (1) study the spatial heterogeneity of pollutants with different land-use types by using statistical description and geostatistical methods; (2) assess the sediments nitrogen and phosphorus pollution, and evaluate the degree of heavy metal pollution and ecological risk in different regions by the geological accumulation index and the potential ecological risk index; (3) identify the main sources of pollutants; and (4) analyze the influence of land-use change on contaminants.

\section{Materials And Methods}

\section{Study area}

Zaozhadian Lake is located in Hebei Province of North China Plain, which is adjacent to Tianjin and Beijing. Zaozhadian Lake is part of Baiyangdian Lake, which is the largest wetland in the North China. The Zaozhadian Lake plays an important role in reducing the pollution load of the Baiyangdian Lake and adjusting the regional climate. The average annual precipitation in this

Peer) reviewing PDF | (2021:09:65482:2:0:NEW 13 Jan 2022) 
101

102

103

104

105

106

107

108

109

110

111

112

113

114

115

116

117

118

119

120

121

122

123

124

125

126

127

128

129

130

131

132

133

134

region is $563.9 \mathrm{~mm}$. Also, the distribution of precipitation along the area during the whole year is extremely unbalanced, with an 80\% from June to August (Wang et al., 2020; Yang et al., 2020).

Caohe River, Baohe River, Fuhe River are rivers located upstream of Zaozhadian Lake, and these rivers are also considered to be important water sources of the Baiyangdian Lake.

However, domestic sewage and industrial wastewater are usually discharged into these rivers. Recently, the lack of precipitation and intensive human activities have led to the ecological degradation of the study area (Zhang et al., 2020), and the land-use types have undergone several changes. For instance, the water area was reduced and the sediments were exposed from 1999 to 2018. At the same time, the cultivated land, ditches, and construction land showed an overall increasing trend (Lv et al., 2020). However, the ecological degradation of Zaozhadian Lake has greatly reduced its ability to purify pollutants.

\section{Sample collection and analysis}

Fig. 1 shows the 25 sampling sites collected on September 2019 and used in this study. Sample collecting were approved by the Major Science Technology Program for Water Pollution Control and Treatment of China (2018ZX07110). These sampling sites were based on three land-use types, i.e., farmland (10 sites, N1-10), lake (9 sites, D1-9), and ditches (6 sites, H1-6). A grab dredger was used to collect the surface sediments $(0-10 \mathrm{~cm})$ in ditches and lake area, and an original soil extractor was used to collect surface soil $(0-10 \mathrm{~cm})$ in farmland. Samples were placed in polyethylene bags and brought to the laboratory. After the samples were freeze-dried, the animal and plant residues and other remnants were removed. $\mathrm{Pb}, \mathrm{Zn}, \mathrm{Cu}, \mathrm{Cr}, \mathrm{Cd}$, and $\mathrm{Ni}$ were determined using flame atomic absorption spectrophotometry (TAS-990 Super AFG) (Ai et al., 2016). Hg and As were determined using microwave digested-atomic fluorescence spectrometric (AFS-8520) (Zhao et al., 2007). Total phosphate was determined by the sulfuric acid and perchloric acid digestion method (Huang et al., 2016). Total nitrogen was determined by the micro-Kjeldahl method, and organic matter was determined by the potassium dichromate oxidation method ( $\mathrm{Bao}, 2000)$. The $\mathrm{pH}$ was measured by portable $\mathrm{pH}$ analyzer (PHS-3C, INESA) using a 1:2.5 $(w / v)$ suspension of solids in water. In the experiment process, the analytical work obeyed the quality control guideline. All samples were analyzed in triplicate and the deviation of duplicate samples was less than $5 \%$.

\section{Evaluation method}

Nemerow pollution index. The Nemerow pollution index is used to evaluate nutrients in the sediments, which is convenient to compare the overall pollution degree of the target area with other regions (Pandit et al., 2020). This method considers the average and maximum value of the pollution index of a single element. The formula is based on Li et al. (2021), as follows:

$P_{i}=C_{i} / k_{i}$

$P_{n}=\left(\sqrt{\bar{P}_{i}^{2}+\left[\max \left(P_{i}\right)\right]^{2}}\right) / 2$ 
135

136

137

138

139

140

141

142

143

144

145

146

147

148

149

150

151

152

153

154

155

156

$$
\begin{aligned}
R I & =\sum_{i=1}^{n} E_{r}^{i}=\sum_{i=1}^{n} T_{r}^{i} \times C_{f}^{i}, \\
E_{r}^{i} & =T_{r}^{i} \times C_{f}^{i}, \\
C_{f}^{i} & =C^{i} / C_{n}^{i} .
\end{aligned}
$$

157

where, $P_{i}$ is the single factor index, $C_{i}$ is the measured value, and $k_{i}$ is the standard value. The standard values of the two indicators (TN and TP) used in this study refer to the sediment evaluation guidelines issued by the Ministry of Environment and Energy of Ontario, Canada. Considering the lowest level degree of ecotoxicity effect in the evaluation guidelines as the standard, the standard values of TN and TP were 0.55 and $0.60 \mathrm{~g} / \mathrm{kg}$, respectively (Ye et al., 2019). $\bar{P}_{i}$ is the average index of pollutants, $\max \left(P_{i}\right)$ is the maximum pollution index of a single pollutant. The pollution level classification is shown in Table S1.

Geological accumulation index. This method uses the relationship between heavy metal content and geochemical background value to evaluate the degree of heavy metal pollution. The $I_{g e o}$ is calculated using the following equation:

$I_{g e o}=\log _{2}\left(C_{n} / k B_{n}\right)$

where, $C_{n}$ is the measured content of the heavy metal, $B_{n}$ is the geological background value of the heavy metal. The background values of soils elements in Hebei Province were used in this study (China Environmental Monitoring Station, 1990) (Xiang et al., 2020). Therefore, the background values for $\mathrm{As}, \mathrm{Cd}, \mathrm{Cu}, \mathrm{Cr}, \mathrm{Ni}, \mathrm{Pb}, \mathrm{Hg}$ and $\mathrm{Zn}$ were 13.6, 0.094, 21.8, 68.3, 30.8, $21.5,0.15$, and $78.4 \mathrm{mg} / \mathrm{kg}$, respectively. $k$ is the correction coefficient, which is determined according to the change of the background value caused by the rock difference in various places. In this case, this value is generally equal to 1.5 (Zhuang et al., 2021). Also, it is divided into seven levels according to the $I_{g e o}$. The specific pollution degree is shown in Table S2.

Potential ecological risk index. RI is a comprehensive potential ecological hazard index. Compared with the $I_{g e o}$, the RI method considers the toxicity of the pollutants (Lars, 1980), gives the biological toxicity coefficients of eight pollutants, and divides the potential ecological hazard levels quantitatively (Men et al., 2018). The calculation formula is:

where, $E_{r}^{i}$ is the potential ecological risk index of a single heavy metal, $T_{r}^{i}$ is the heavy metal biological toxicity response coefficient $(\mathrm{As}=10, \mathrm{Cd}=30, \mathrm{Cr}=2, \mathrm{Cu}=\mathrm{Ni}=\mathrm{Pb}=5, \mathrm{Zn}=1, \mathrm{Hg}=40$ ).

$C_{n}^{i}$ is the background reference value of the heavy metal, and $C^{i}$ is the actual content of the heavy metal. The evaluation criteria for potential ecological hazards are shown in Table S3.

\section{Statistical analysis}

The spatial distribution of the contaminant was mapped by geo-statistical method (Kriging interpolation, ArcGIS 10.4) (Ganugapenta et al., 2018). To test the effect of land-use types on pollutants, multivariate analysis of variance was conducted by IBM SPSS Statistics 24. Dual 
165 hierarchical clustering analysis is widely used in the analysis of environmental factors ( $\mathrm{Li}$ et al.,

166

167

168

169

170

171

172

173

174

175

176

177

178

179

180

181

182

183

184

185

186

187

188

189

190

191

192

193

194

195

196

197

198

199

200

201

202

203

2015). Dual hierarchical clustering analysis was performed using the heat map dendrogram tool of Origin 2018 to group the similar points and identify specific areas of contaminants. Principal component analysis was performed using $\mathrm{R}$ software to further analyze the relationship between contaminants (Xu et al., 2014). The script for principal component analysis is in supplementary files.

\section{Results}

\section{Spatial distribution of contaminants}

The distribution of TN, TP, OM, and pH are presented in Fig. 2. OM and TN had similar spatial distribution characteristics, and the area with the higher TN and OM was located in the east of the study area, which corresponded to one land-use type: lake area. The contents of TN and OM in the lake area were $3.92 \pm 0.69 \mathrm{~g} \cdot \mathrm{kg}^{-1}$ and $60.61 \pm 8.91 \mathrm{~g} \cdot \mathrm{kg}^{-1}$ respectively (Table 1). The average content of TN and OM was in the following order: lake $>$ farmland $>$ ditch. On the contrary, the higher $\mathrm{pH}$ was in the west, corresponding to the farmland area. The area with the higher TP content was located in the south of the study area, close to a village. The average content of TP in lake, farmland, and ditches were $0.93 \mathrm{~g} \cdot \mathrm{kg}^{-1}, 0.89 \mathrm{~g} \cdot \mathrm{kg}^{-1}, 0.91 \mathrm{~g} \cdot \mathrm{kg}^{-1}$, respectively.

There was a regional difference in heavy metals (Fig. 3). The area with higher heavy metal content was the farmland. The heavy metals $\mathrm{Cr}$ and $\mathrm{Ni}$ had similar distributions and the content gradually decreased from west to east. The content of $\mathrm{Cu}, \mathrm{Zn}, \mathrm{As}$, and $\mathrm{Hg}$ were generally higher in the south and lower in the north. These four pollutants were mainly concentrated in farmland areas. $\mathrm{Pb}$ and $\mathrm{Cd}$ were mainly concentrated in the middle of the study area, and their contents diffused to the surroundings and decreased. The results of multivariate analysis of variance showed that land-use type had a significant impact on the distribution of pollutants $(p<0.05)$ (Table S4). The average contents of all heavy metals and As in farmland soil were higher than those in lake and ditch sediments (Table 1). The heavy metals $\mathrm{Pb}, \mathrm{Cu}$, and $\mathrm{Ni}$ exceeded the background value in three land-use types. The content of $\mathrm{Zn}$ in farmland and lake area was higher, which exceeded the background value by 1.22 and 1.13 times, respectively. The $\mathrm{Cd}$ in the farmland exceeded the background value by 1.06 times. Moreover, the content of $\mathrm{Cr}$, As, and $\mathrm{Hg}$ were lower than the background value in all regions.

\section{Evaluation of total nitrogen and total phosphorus}

The pollution index of TN and TP at each sampling point of the lake and ditch area was greater than 1 (Table S5), indicating that there were nitrogen and phosphorus pollution $\left(1.32<P_{T N}<\right.$ $\left.8.69,1.18<P_{T P}<2.35\right)$. Nitrogen pollution of sediments in the study area showed spatial differences. The $P_{T N}$ ranges of ditches and lake areas were 1.32-5.56 and 2.91-8.69, respectively. All points in the lake area were heavily polluted, except for D9. In fact, the degree of TP pollution varied among different regions, except for two sampling points, N6 and D8, which were moderately polluted, and other points were slightly polluted. The comprehensive pollution index showed that more than $90 \%$ of the lake area was seriously polluted by nitrogen and phosphorus. 
204 Pollution evaluation and risk assessment of heavy metals and As

205 The $I_{\text {geo }}$ values of all the analyzed metals $(\mathrm{Pb}>\mathrm{Cu}>\mathrm{Ni}>\mathrm{Zn}>\mathrm{Cd}>\mathrm{As}>\mathrm{Cr}>\mathrm{Hg}$ ) were 0.49, $2060.28,0.18,-0.45,-0.99,-1.06,-1.17$, and -3.03 , respectively (Fig. 4). Among them, the $\mathrm{Pb}, \mathrm{Cu}$, 207 and Ni pollution degree was "low polluted" showing an $I_{g e o}$ range of 0 to 1 . The $I_{g e o}$ of other 208 heavy metals was less than 0 , indicating that their pollution degree was "unpolluted". The metal 209 pollution levels of the three land types were consistent with the overall pollution levels. Fig. $4 \mathrm{~d}$ 210 shows that the range of $I_{g e o}$ in the lake area is very small, indicating that the sources or 211 accumulation modes of heavy metals at different lake points are similar. The wide range of $I_{g e o}$ 212 in farmland and ditches indicates the accumulation of heavy metals in farmland and ditches is 213 affected by multiple pollution sources.

214 The order of the $E_{r}^{i}$ values was $\mathrm{Cd}>\mathrm{Pb}>\mathrm{Cu}>\mathrm{Ni}>\mathrm{As}>\mathrm{Hg}>\mathrm{Cr}>\mathrm{Zn}$ (Fig. 5), and the $E_{r}^{i}$ of 215 the eight elements were all lower than 40, indicating low ecological risks. The dominant factor 216 affecting $R I$ was $\mathrm{Cd}$, which represents the possible ecological risk to the biological community. 217 The $E_{r}^{i}$ values of $C d$ in farmland, ditch, and lake were 31.28, 14.36, 27.30, respectively, which 218 were different and indicated a higher potential ecological risk of $\mathrm{Cd}$ in farmland. The $R I$ values 219 of the three land-use types in the study area were 84.21, 71.34, 50.78 for farmland $>$ lake $>$ ditch, 220 respectively. Therefore, the potential ecological risk of heavy metals in the farmland was higher 221 than that in other regions. Comprehensive analysis showed that the rankings of the $I_{g e o}$ and $E_{r}^{i}$ 222 were different. Moreover, both indicated that $\mathrm{Pb}, \mathrm{Cu}$ and $\mathrm{Ni}$ ranked higher and represented the 223 main heavy metal risk factors.

\section{Mutivariate statisistical analysis}

225 Dual hierarchical clustering analysis showed that all elements were divided into two major 226 categories (Fig. 6). The first category was TN, TP, OM and the second category was As and 227 heavy metals. The indicators were further clustered and divided into four categories. $\mathrm{Cr}$ was a 228 single cluster, and the main pollution sites were N1, N2, and N3. In addition, Cd was located in a 229 single cluster, and the concentration at N5, N6, N7, and N10 was significantly higher than 230 compared to other sites. $\mathrm{Pb}, \mathrm{Zn}, \mathrm{Cu}, \mathrm{Ni}, \mathrm{As}$, and $\mathrm{Hg}$ were classified into one category, indicating 231 that the distribution of these elements was similar. Moreover, TN, OM, and TP were classified 232 into one category. Furthermore, a horizontal dendrogram clustering was performed, resulting in 233 five clusters. The farmland points were mainly found in the fifth cluster, lake points were in the 234 fourth cluster, and ditch points were in the first, third, fourth, and fifth clusters. The clustering 235 arrangement agreed to the actual pollution distribution of study area. Heavy metals and As were 236 high in farmland soils, while nutrients were high in lake sediments.

237 The principal component analysis showed that the eigenvalues of the four principal 238 components greater than 1 explained $84.2 \%$ of the total variance (Table S6). The PC1 explained 239 the variance of $39.8 \%$, which included $\mathrm{Cu}, \mathrm{Ni}, \mathrm{As}, \mathrm{Pb}$, and $\mathrm{Zn}$. The PC2 accounted for $22.1 \%$ of 240 the total variance, which was related to TN and OM. Finally, PC3 and PC4 were dominated by $241 \mathrm{Cr}$ and $\mathrm{Cd}$, respectively. The relationship between pollutants is consistent with the results of 242 Pearson correlation analysis (Fig. S1). Fig. 7 shows the contribution of elements to the sampling 
243 point. The sampling points in the lake area were mainly found in the first and second quadrants,

$244 \mathrm{TN}$ and $\mathrm{OM}$ were the main pollutants, and $\mathrm{Cd}, \mathrm{Zn}$, and TP also contributed to the first quadrant.

245 Moreover, the farmland sampling points were in the fourth quadrant, and these sampling points

246 were mainly affected by $\mathrm{Ni}, \mathrm{As}, \mathrm{Cu}, \mathrm{Cr}, \mathrm{Pb}$, and $\mathrm{Zn}$. Additionally, the points of the ditches were

247 relatively scattered, probably due to the surrounding environment which can have a great impact

248 on these points.

249 Discussion

250 Pollution source identification

251 Dual hierarchical clustering analysis and principal component analysis showed that $\mathrm{Cu}, \mathrm{Ni}, \mathrm{As}$, $252 \mathrm{~Pb}$, and $\mathrm{Zn}$ had similar sources in the study area. Specifically, the average values of $\mathrm{Cu}, \mathrm{Ni}, \mathrm{Pb}$, 253 and $\mathrm{Zn}$ exceed the background value, except for As. In fact, these contaminants had the highest

254

255

256

257

258

259

260

261

262

263

264

265

266

267

268

269

270

271

272

273

274

275

276

277

278

279

280

281 contents in farmland soils. Previous studies have shown that the raw material for producing phosphate fertilizers contains As (Gupta et al., 2014). And in the production process of phosphate fertilizer, heavy metals may also be brought into the fertilizer (Zhang et al., 2016). Therefore, the long-term use of phosphorus fertilizer may be the main cause for the high content of heavy metals and As in farmlands. In addition, some pesticides such as organic arsenic fungicides and lead arsenate pesticides contain heavy metals. Consequently, the use of pesticides can also contribute to pollution by heavy metals (Fallah et al., 2021). Therefore, $\mathrm{Cu}, \mathrm{Ni}, \mathrm{As}, \mathrm{Pb}$, and $\mathrm{Zn}$ may be identified as an agricultural source. $\mathrm{Cr}$ is a group of its own. The $\mathrm{Cr}$ content in the three land-use types was lower than the background value, which indicated that the sediments and soils were not polluted by $\mathrm{Cr}$. These results suggest that $\mathrm{Cr}$ could mainly come from a geological but not an anthropogenic source. The analysis result of $\mathrm{Cd}$ shows that it has different pollution sources from other elements. Previous research has shown that the main sources of $\mathrm{Cd}$ in soils are mining, industry, and automobile pollution (Das, Samantaray \& Rout, 1997).

Previously, there were many companies involved in papermaking, electric power, printing, and dyeing in the upstream of the study area. In fact, industrial wastewater was discharged into the Fuhe River and then flowed into wetland (Hu et al., 2011). Thus, Cd may come from industrial sources.

The sources of TN and OM were similar. The content of TN and OM in lake sediments was higher than that of farmland and ditches. In fact, dead organisms such as plants, algae, and mollusks in the lake can accumulate in the benthic zone of the lake, merging with the clay silt (Xing et al., 2021). Also, the poor water flow of Zaozhadian Lake is more likely to cause a reduction environment at the bottom of the lake, promoting the accumulation of TN and OM in sediments. Therefore, $\mathrm{TN}$ and $\mathrm{OM}$ in sediments mainly come from animal and plant residues. Studies have shown that one of the main factors for the changes in OM and TN content in the wetland could be the types of vegetation (Zhao et al., 2020). Also, point source pollution will directly affect the distribution of pollutants (Yang et al., 2018). As mentioned above, the nearby villages in the middle of the study area had the highest TP content. In this area, most of the poultry was raised on the nearby water surface, so the feces were directly discharged into the

Peer) reviewing PDF | (2021:09:65482:2:0:NEW 13 Jan 2022) 
282 lake. Moreover, the villagers directly discharged domestic sewage into the water area, which also 283 resulted in higher TP content.

284 The impact of land-use type changes on the pollutants

285 The TN, TP, and OM in farmland are lower than other land-use types, which means that the soil 286 nutrients decreased after the lake area was converted to farmland. Firstly, the accumulation of 287 nutrients in soil decreases due to the reduction of aquatic animals and plant decay. Secondly, 288 crops need to absorb nutrients in the growth process, and long-term planting of crops consumes 289 nutrients in the soil. Finally, long-term traditional farming destroyed soil aggregates and 290 accelerated the loss of soil organic matter (Chambers et al., 2014).

291

292

293

294

295

296

297

298

299

The data presented in this study and in Zheng et al. (2016) showed that heavy metals content increased after the lake area was transformed into cropped land. The conversion of lake area to farmland increased the way for heavy metals to enter the wetlands. Cultivation typically increases the input of agrochemicals in the form of fertilizers, pesticides, and manures, which has led to the enrichment of some heavy metals in soil (Wang \& Xu, 2015). However, many studies also showed that soil heavy metals decreased after lake was converted to farmland (Bai et al., 2010). The reason for these variances is due to the difference in soil properties and cultivation practices that alter the geochemical behavior of heavy metals in soils (Sun et al., 2019; Jiao et al., 2014). Moreover, the conversion of land-use type could also change the physical and

300

301

302

303

304

305

306

307

308

309

310

311

312

313

314

315

316

317

318

319

320

321

chemical properties of soil. For instance, it has been widely reported that the soil organic matter has a large capacity for sorption of heavy metals in the soils (yan et al., 2017). In this study, the content of organic matter in sediments decreased from $60.61 \pm 8.91 \mathrm{~g} \cdot \mathrm{kg}^{-1}$ to $30.86 \pm 8.45 \mathrm{~g} \cdot \mathrm{kg}^{-1}$ after the lake was transformed into farmland. Therefore, the consumption of organic matter reduced the ability of soil to retain heavy metals, which may result in an increase of heavy metal mobility and phytotoxicity in study area.

\section{Implications for land-use planning and water quality maintenance}

In farmlands, most of the heavy metals in the soil have originated mostly from man-made sources than natural sources. After the lake was transformed into farmland, the accumulation of heavy metals in wetland system accelerated. Heavy metals are overloaded in soils cause a severe environmental risk. In addition, heavy metals from farmland soils can be released to lakes through agricultural runoff and affect aquatic communities (Fernández et al., 2005). For lakeshore wetlands, these effects are more obvious because the lake water is stagnant, allowing heavy metals to easily accumulate (Sun et al., 2019). A greater area of farmland can result in a high risk to the regional environmental system. Relevant departments should take effective measures to reduce the toxic risks of contaminants through exogenous control and to adjust the land pattern of the Zaozhadian Lake.

The results of this study provide useful information that can be used to emphasize on potential long-term impacts of land-use type change to mitigate or minimize negative impacts. However, this study was unable to demonstrate any relationship between changes of soil properties and the migration of pollutants. Changes in water content, exposure to the air, crops grown and methods of fertilization create a complex scenario that influences pollutant migration, which should be

Peer) reviewing PDF | (2021:09:65482:2:0:NEW 13 Jan 2022) 
322 further studied. Moreover, we suggest that the adjustment of wetland land-use types should be

323

324

325

326

327

328

329

330

331

332

333

334

335

336

337

338

339

340

341

342

343

344

345

346

347

348

349

350

351

352

353

354

355

356

357

358

359

360

based on clarifying the factors affecting the migration and transformation of pollutants and changes in toxicity.

\section{Conclusions}

Spatially, there were differences in pollutant content under different land-use types. The sediments in the lake area have high TN and OM content, and the farmland soils have a higher content of heavy metals. Also, Zaozhadian Lake soils can be described as low polluted by heavy metals. Among the selected heavy metals, $\mathrm{Pb}$ shows the highest degree of pollution and $\mathrm{Cd}$ shows the highest ecological risk. Moreover, the pollution level of heavy metals in the farmland area was lightly polluted, and most of the ditches and lake areas were not polluted. Furthermore, $\mathrm{Cu}, \mathrm{As}, \mathrm{Ni}, \mathrm{Pb}$, and $\mathrm{Zn}$ were primarily derived from agriculture pollution (e.g. phosphate fertilizer and pesticides). In contrast, $\mathrm{Cd}$ and $\mathrm{Cr}$ mainly originated from industrial and natural sources, respectively. The nutrients were generally controlled by the decomposition of aquatic animal and plant and human activities. Land use changes could affect some contaminants concentrations in wetland soils. The change of lake to farmland decreased the concentrations of TN and OM, and increased the concentrations of heavy metals and As. Relevant departments should take effective measures to reduce the toxic risks of contaminants through exogenous control and to adjust the land pattern of the Zaozhadian Lake. Additionally, the effects of changes in soil properties on pollutant migration and toxicity should be further studied.

\section{Acknowledgements}

We thank our colleagues and research staff members for their constructive advice and help.

\section{References}

Acharya RP, Maraseni T, Cockfield G. 2019. Global trend of forest ecosystem services valuation-an analysis of publications. Ecosystem Services 39:100979 DOI 10.1016/j.ecoser.2019.100979.

Ai S, Guo R, Liu B, Ren L, Naeem S, Zhang W, Zhang Y. 2016. A field study on the dynamic uptake and transfer of heavy metals in Chinese cabbage and radish in weak alkaline soils.

Environmental Science and Pollution Research 23(20):20719-20727 DOI 10.1007/s11356-0167277-x.

Alahabadi A, Malvandi H. 2018. Contamination and ecological risk assessment of heavy metals and metalloids in surface sediments of the Tajan River, Iran. Marine Pollution Bulletin 133:741749 DOI 10.1016/j.marpolbul.2018.06.030.

Bai J, Yang Z, Cui B, Gao H, Ding Q. 2010. Some heavy metals distribution in wetland soils under different land use types along a typical plateau lake, China. Soil \& Tillage Research 106(2):344-348 DOI 10.1016/j.still.2009.11.003.

Bao SD. 2000. Soil agrochemical analysis. Third Edition. Beijing: China Agriculture Press.Chambers LG, Davis SE, Troxler T, Boyer JN, Downey-Wall A, Scinto LJ. 2014. Biogeochemical effects of simulated sea level rise on carbon loss in an Everglades mangrove peat soil. Hydrobiologia 726(1):195-211 DOI 10.1007/s10750-013-1764-6. 
361 Conley DJ, Paerl HW, Howarth RW, Boesch DF, Seitzinger SP, Havens KE, Lancelot C, Likens 362 GE. 2009. ECOLOGY Controlling Eutrophication: Nitrogen and Phosphorus. Science 363 323(5917):1014-1015 DOI 10.1126/science.1167755.

364 Das P, Samantaray S, Rout GR. 1997. Studies on cadmium toxicity in plants: A review.

365 Environmental Pollution 98(1):29-36 DOI 10.1016/S0269-7491(97)00110-3.

366 Ding XS, Shan XJ, Chen YL, Li M, Li JJ, Jin XS. 2020. Variations in fish habitat fragmentation 367 caused by marine reclamation activities in the Bohai coastal region, China. Ocean \& Coast 368 Management 184:105038 DOI 10.1016/j.ocecoaman.2019.105038.

369 Fallah Z, Zare EN, Ghomi M, Ahmadijokani F, Amini M, Tajbakhsh M, Arjmand M, Sharma G, 370 Ali H, Hmad A, Makvandi P, Lichtfouse E, Sillanpaa M, Varma RS. 2021. Toxicity and 371 remediation of pharmaceuticals and pesticides using metal oxides and carbon nanomaterials.

372 Chemosphere 275:130055 DOI 10.1016/j.chemosphere.2021.130055.

373 Fernández MD, Cagigal E, Vega MM, Urzelai A, Babín M, Pro J, Tarazona JV. 2005. Ecological

374 risk assessment of contaminated soils through direct toxicity assessment. Ecotoxicology and

375 Environmental Safety 62(2):174-184 DOI 10.1016/j.ecoenv.2004.11.013.

376 Ganugapenta S, Nadimikeri J, Chinnapolla SRRB, Ballari L, Madiga RKN, Tella LP. 2018.

377 Assessment of heavy metal pollution from the sediment of Tupilipalem Coast, southeast coast of

378 India. International Journal of Sediment Research 33(3):294-302 DOI

379 10.1016/j.ijsrc.2018.02.004.

380 Gupta DK, Chatterjee S, Datta S, Veer V, Walther C. 2014. Role of phosphate fertilizers in 381 heavy metal uptake and detoxification of toxic metals. Chemosphere 108:134-144 DOI 382 10.1016/j.chemosphere.2014.01.030.

383 Huang L, Li Z, Bai X, Li R, Wu H, Wei D, Yu L. 2016. Laboratory study of phosphorus 384 retention and release by eutrophic lake sediments: modeling and implications for P release 385 assessments. Ecological Engineering 95:438-446 DOI 10.1016/j.ecoleng.2016.06.089.

$386 \mathrm{Hu}$ G, Xu M, Xu Z, Dai J, Cao H, Peng X, Qi J. 2011. Pollution characteristic and potential risk 387 assessment of heavy metals in surface sediment from Fuhe River and Baiyangdian Lake, North 388 China. Journal of Agro-Environment Science 30(1):146-153.

389 Hu S, Niu Z, Chen Y, Li L, Zhang H. 2017. Global wetlands: potential distribution, wetland loss, 390 and status. Science of The Total Environment 586:319-327 DOI

391 10.1016/j.scitotenv.2017.02.001.

392 Jiang XL, Xiong ZQ, Liu H, Liu GH, Liu WZ. 2017. Distribution, source identification, and 393 ecological risk assessment of heavy metals in wetland soils of a river-reservoir system.

394 Environmental science and pollution research 24(1):436-444 DOI 10.1007/s11356-016-7775-x. 395 Jiao W, Ouyang W, Hao F, Liu B, Wang F. 2014. Geochemical variability of heavy metals in 396 soil after land use conversions in Northeast China and its environmental applications.

397 Environmental Science-Processes \& Impacts 16(4):924-931 DOI 10.1039/c3em00535f.

398 Ji Z, Zhang H, Zhang Y, Chen T, Long Z, Li M, Pei Y. 2019a. Distribution, ecological risk and 399 source identification of heavy metals in sediments from the Baiyangdian Lake, Northern China. 400 Chemosphere 237:124425 DOI 10.1016/j.chemosphere.2019.124425. 
401 Ji Z, Zhang Y, Zhang H, Huang C, Pei Y. 2019b. Fraction spatial distributions and ecological 402 risk assessment of heavy metals in the sediments of Baiyangdian Lake. Ecotoxicology and 403 Environmental Safety 174:417-428 DOI 10.1016/j.ecoenv.2019.02.062.

404 Lars H. 1980. An ecological risk index for aquatic pollution control, a sedimentological 405 approach. Water Research 14(8):975-1001 DOI 10.1016/0043-1354(80)90143-8.

406 Li H, Zhang Y, Wu L, Jin Y, Gong Y, Li A, Li J, Li F. 2021. Recycled aggregates from 407 construction and demolition waste as wetland substrates for pollutant removal. Journal of 408 Cleaner Production 311:127766 DOI 10.1016/j.jclepro.2021.127766.

409 Li J, Jia C, L, Y, Tang S, Shim H. 2015. Multivariate analysis of heavy metal leaching 410 from urban soils following simulated acid rain. Microchemical journal 122:89-95 DOI 411 10.1016/j.microc.2015.04.015.

412 Liu W, Guo Z, Jiang B, Lu F, Wang H, Wang D, Zhang M, Cui L. 2020. Improving wetland 413 ecosystem health in China. Ecological Indicators 113:106184 DOI

414 10.1016/j.ecolind.2020.106184.

415 Lu A, Li B, Li J, Chen W, Xu L. 2018. Heavy metals in paddy soil-rice systems of industrial and 416 township areas from subtropical China: Levels, transfer and health risks. Journal of Geochemical 417 Exploration 194:210-217 DOI 10.1016/j.gexplo.2018.08.003.

418 Lu Q, Bai J, Zhang G, Wu J. 2020. Effects of coastal reclamation history on heavy metals in 419 different types of wetland soils in the Pearl River Delta: Levels, sources and ecological risks. 420 Journal of Cleaner Production 272:122668 DOI 10.1016/j.jclepro.2020.122668.

421 Lv T, Li L, Zhu S, Yang G, Ma H. 2020. Analysis on land use variation law and its driving force 422 of Baiyangdian Lake since recent 30 years. Water Resources and Hydropower Engineering 423 51(3):37-44 DOI 10.13928/j.cnki.wrahe.2020.03.005.

424 Men C, Liu R, Xu F, Wang Q, Guo L, Shen Z. 2018. Pollution characteristics, risk assessment, 425 and source apportionment of heavy metals in road dust in Beijing, China. Science of The Total 426 Environment 612:138-147 DOI 10.1016/j.scitotenv.2017.08.123.

427 Pandit P, Mangala P, Saini A, Bangotra P, Kumar V, Mehra R, Ghosh D. 2020. Radiological and 428 pollution risk assessments of terrestrial radionuclides and heavy metals in a mineralized zone of 429 the siwalik region (India). Chemosphere 254:126857 DOI 10.1016/j.chemosphere.2020.126857. 430 Puthusseri RM, Nair HP, Johny TK, Bhat SG. 2021. Insights into the response of mangrove 431 sediment microbiomes to heavy metal pollution: Ecological risk assessment and metagenomics 432 perspectives. Journal of Environmental Management 298:113492 DOI 433 10.1016/j.jenvman.2021.113492.

$434 \mathrm{Pu}$ X, Cheng HG, Tysklind M, Xie J, Lu L, Yang S. 2017. Occurrence of water phosphorus at 435 the water-sediment interface of a freshwater shallow lake: Indications of lake chemistry.

436 Ecological Indicators 81:43-452 DOI 10.1016/j.ecolind.2017.06.006.

437 Ramsar Convention on Wetlands (RCW). 2018. Global Wetland Outlook: State of the World's 438 Wetlands and their Services to People. Ramsar Convention Secretariat, Gland, Switzerland. 439 Available at https://ssrn.com/abstract $=3261606$. 
440 Sun C, Zhu S, Zhao B, Li W, Gao X, Wang X. 2019. Effect of Land Use Conversion on Surface 441 Soil Heavy Metal Contamination in a Typical Karst Plateau Lakeshore Wetland of Southwest 442 China. International Journal of Environmental Research and Public Health 17(1):84 DOI 443 10.3390/ijerph17010084.

444 Sun L, Wang J, Wu Yang, Gao T, Liu C. 2021. Community Structure and Function of Epiphytic 445 Bacteria Associated with Myriophyllum spicatum in Baiyangdian Lake, China. Frontiers in 446 microbiology 12:705509 DOI 10.3389/fmicb.2021.705509.

447 Tian SQ, Wang SJ, Bai XY, Zhou DQ, Luo GJ, Wang JF, Wang MM, Lu Q, Yang YJ, Hu ZY, 448 Li CJ, Deng, YH. 2019. Hyperspectral prediction model of metal content in soil based on the 449 genetic ant colony algorithm. Sustainability 11(11):3197 DOI 10.3390/su11113197.

450 Wang J, Zeng X, Xu D, Gao L, Li Y, Gao B. 2020. Chemical fractions, diffusion flux and risk 451 assessment of potentially toxic elements in sediments of Baiyangdian Lake, China. Science of 452 The Total Environment 724:138046 DOI 10.1016/j.scitotenv.2020.138046.

453 Wang X, Gao P, Daping L, Liu J, Yang N, Gu W, He X, Tang W. 2019. Risk assessment for and 454 microbial community changes in Farmland soil contaminated with heavy metals and metalloids. 455 Ecotoxicology and Environmental Safety 185:109685 DOI 10.1016/j.ecoenv.2019.109685.

456 Wang X, Xu Y. 2015. Soil heavy metal dynamics and risk assessment under long-term land use 457 and cultivation conversion. Environmental Science and Pollution Research 22(1) 264-274 DOI 458 10.1007/s11356-014-3340-7.

459 Xiang Y, Wang X, Shan B, Zhao Y, Tang W, Shu L, Jiang S, Cao Y. 2020. Spatial distribution, 460 fractionation and ecological risk of heavy metals in surface sediments from Baiyangdian Lake. 461 Huanjing Kexue Xuebao/Acta Scientiae Circumstantiae 40(6):2237-2246 DOI

$46210.13671 / j . h j k x x b .2020 .0060$.

463 Xing X, Chen M, Wu Y, Tang Y, Li C. 2021. The decomposition of macro-zoobenthos induces 464 large releases of phosphorus from sediments. Environmental Pollution 283:117104 DOI 465 10.1016/j.envpol.2021.117104.

466 Xu J, Guo J, Liu G, Shi G, Guo C, Zhang Y, Feng Y. 2014. Historical trends of concentrations, 467 source contributions and toxicities for PAHs in dated sediment cores from five lakes in western 468 China. Science of The Total Environment 470:519-526 DOI 10.1016/j.scitotenv.2013.10.022. 469 Yang Q, Li Z, Lu X, Duan Q, Huang L, Bi J. 2018. A review of soil heavy metal pollution from 470 industrial and agricultural regions in China: Pollution and risk assessment. Science of The Total 471 Environment 642:690-700 DOI 10.1016/j.scitotenv.2018.06.068.

472 Yang W, Yan J, Wang Y, Zhang B, Wang H. 2020. Seasonal variation of aquatic macrophytes 473 and its relationship with environmental factors in Baiyangdian Lake, China. Science of The Total 474 Environment 708:135112 DOI 10.1016/j.scitotenv.2019.135112.

475 Yan XL, Hu YM, Chang YU, Li HY, Liu M, Zhong JQ, Zhang DH, Wu W. 2017. Effects of land 476 reclamation on distribution of Soil properties and heavy metal concentrations, and the associated 477 environmental pollution assessment. Polish Journal of Environmental Studies 26(4):1809-1823 478 DOI 10.15244/pjoes/68533. 
479 Ye H, Yang H, Han N, Huang C, Huang T, Li G, Yuan X, Wang H. 2019. Risk assessment based 480 on nitrogen and phosphorus forms in watershed sediments: a case study of the upper reaches of 481 the Minjiang watershed. Sustainability 11(20):5565 DOI:10.3390/su11205565.

482 Zhang Q, Xiang R, Liu Z, Wan Y, Zhong Z, You X, Qi Y. 2016. Content and morphology 483 characteristics of heavy metals in phosphate fertilizers in Hunan province. Nonferrous Metals 484 Science and Engineering 7(5):1674-9669 DOI 10.13264/j.cnki.ysjskx.2016.05.022.

485 Zhang Z, Lei L, He Z, Su Y, Li L, Wang X, Guo X. 2020. Tracking Changing Evidences of 486 Water in Wetland Using the Satellite Long-Term Observations from 1984 to 2017. Water 487 12(6):1602 DOI 10.3390/w12061602.

488 Zhao Q, Ding S, Liu Q, Wang S, Jing Y, Lu M. 2020. Vegetation influences soil properties along 489 riparian zones of the Beijiang River in Southern China. Peerj 8:9699 DOI 10.7717/peerj.9699. 490 Zhao Y, Shi X, Huang B, Yu D, Wang H, Sun W, ÖBOERN I, BLOMBÄCK K. 2007. Spatial 491 Distribution of Heavy Metals in Agricultural Soils of an Industry-Based Peri-Urban Area in 492 Wuxi, China. Pedosphere 17(1):44-51 DOI 10.1016/S1002-0160(07)60006-X.

493 Zheng R, Zhao J, Zhou X, Ma C, Wang L, Gao X. 2016. Land Use Effects on the Distribution 494 and Speciation of Heavy Metals and Arsenic in Coastal Soils on Chongming Island in the 495 Yangtze River Estuary, China. Pedosphere 26(1):74-84 DOI 10.1016/S1002-0160(15)60024-8. 496 Zhuang S, Lu X, Yu B, Fan X, Yang Y. 2021. Ascertaining the pollution, ecological risk and 497 source of metal(loid)s in the upstream sediment of Danjiang River, China. Ecological Indicators 498 125(3):107502 DOI 10.1016/j.ecolind.2021.107502. 
Figure 1

Sampling site location

N1-N10, farmland sampling point; H1-H6, ditch sampling point; D1-D9, lake sampling point.

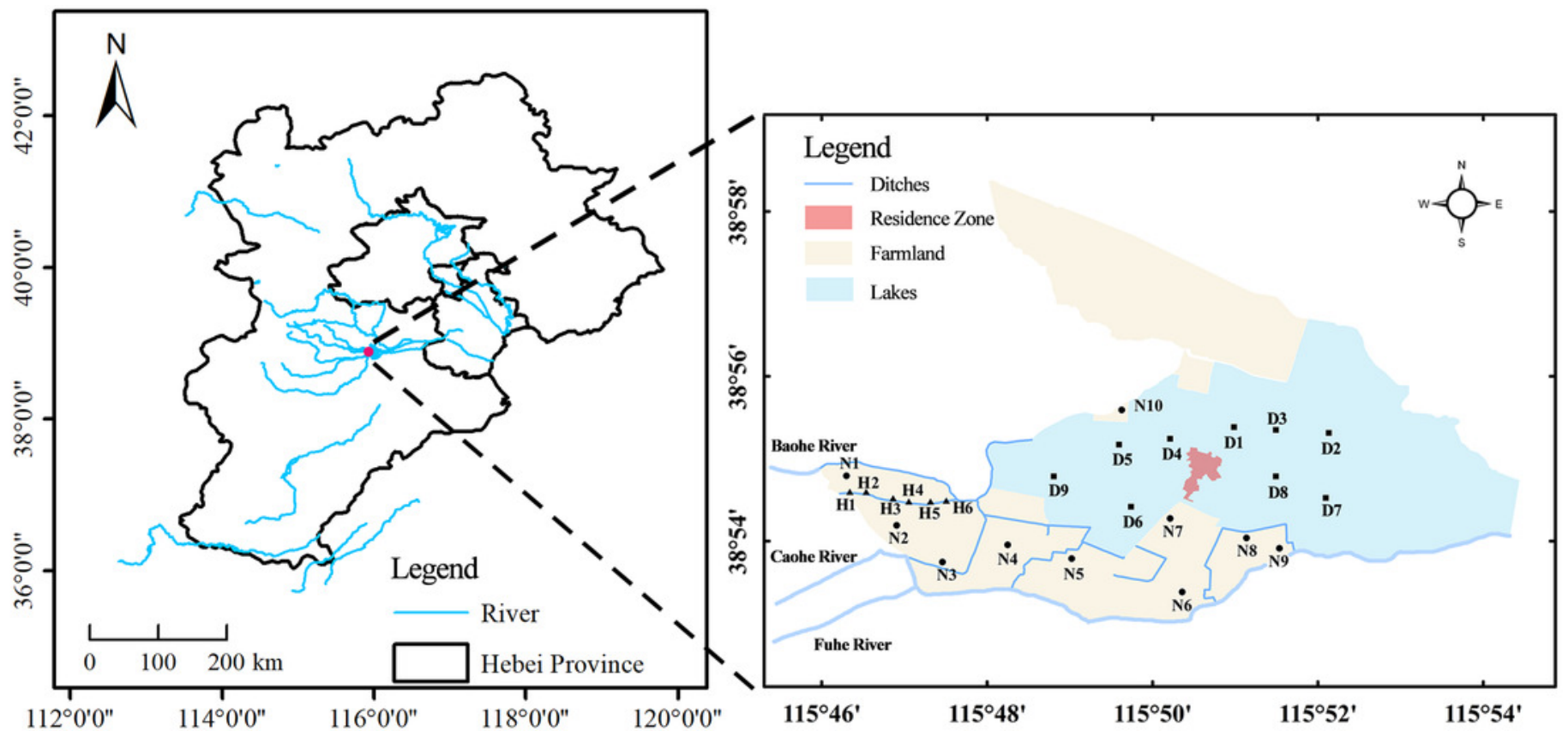


Figure 2

Distribution of nutrients and $\mathrm{pH}$

The spatial distribution of the contaminant was mapped by Kriging interpolation
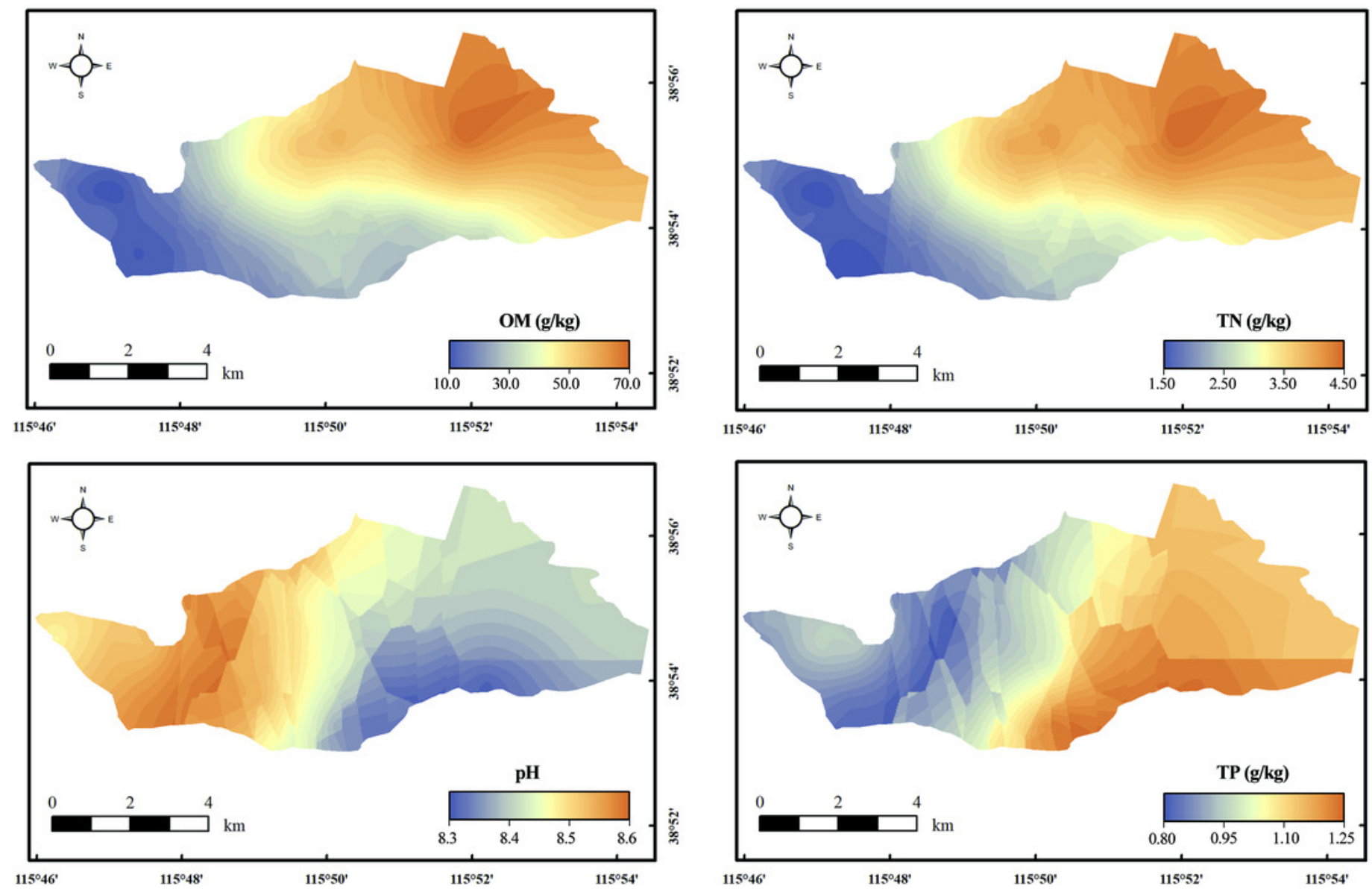
Figure 3

Distribution of heavy metals and As

The spatial distribution of the contaminant was mapped by Kriging interpolation 

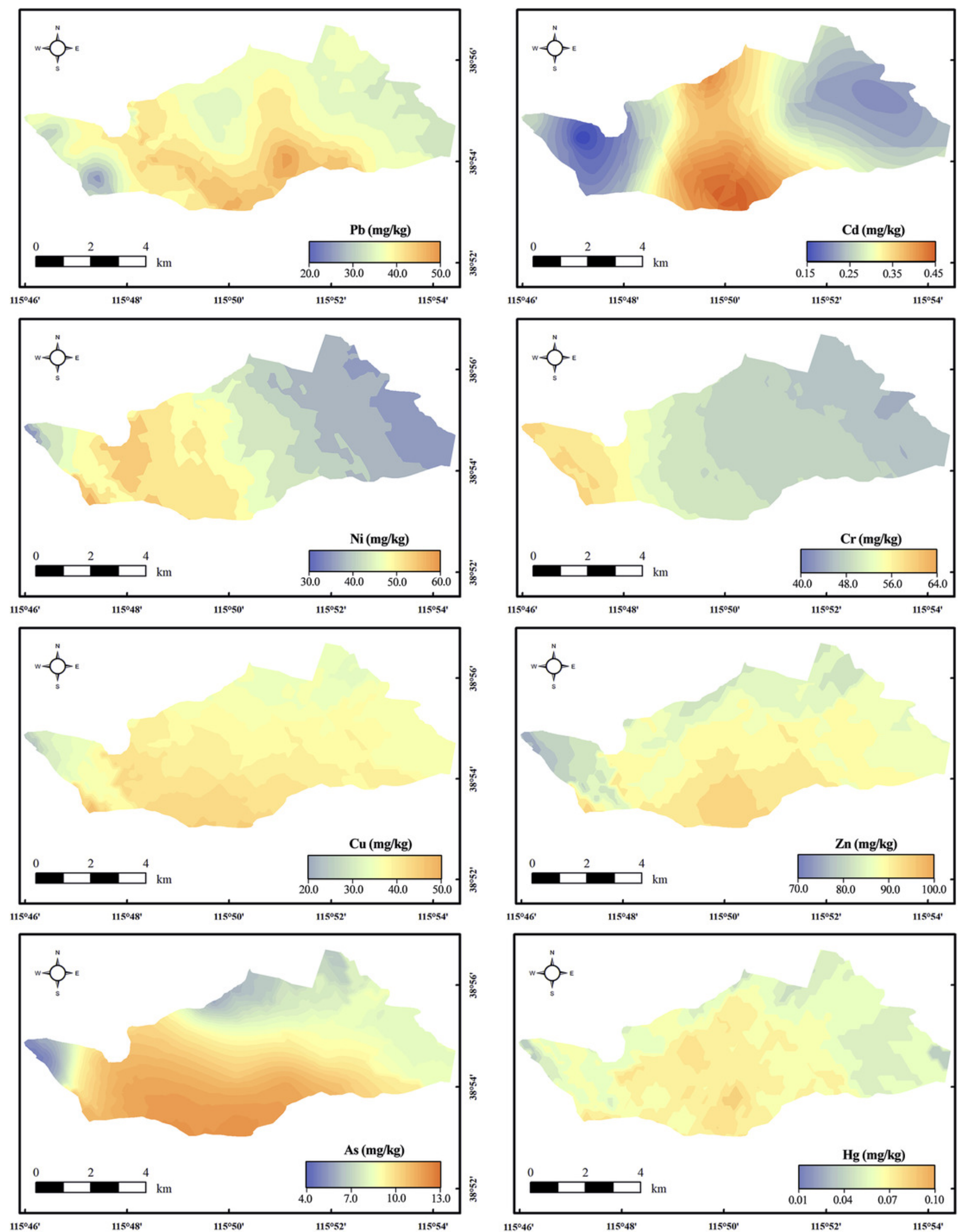

PeerJ reviewing PDF | (2021:09:65482:2:0:NEW 13 Jan 2022) 
Figure 4

$I_{g e o}$ in sediments of different regions

(a) whole study area; (b) farmland; (c) ditch; (d) lake area
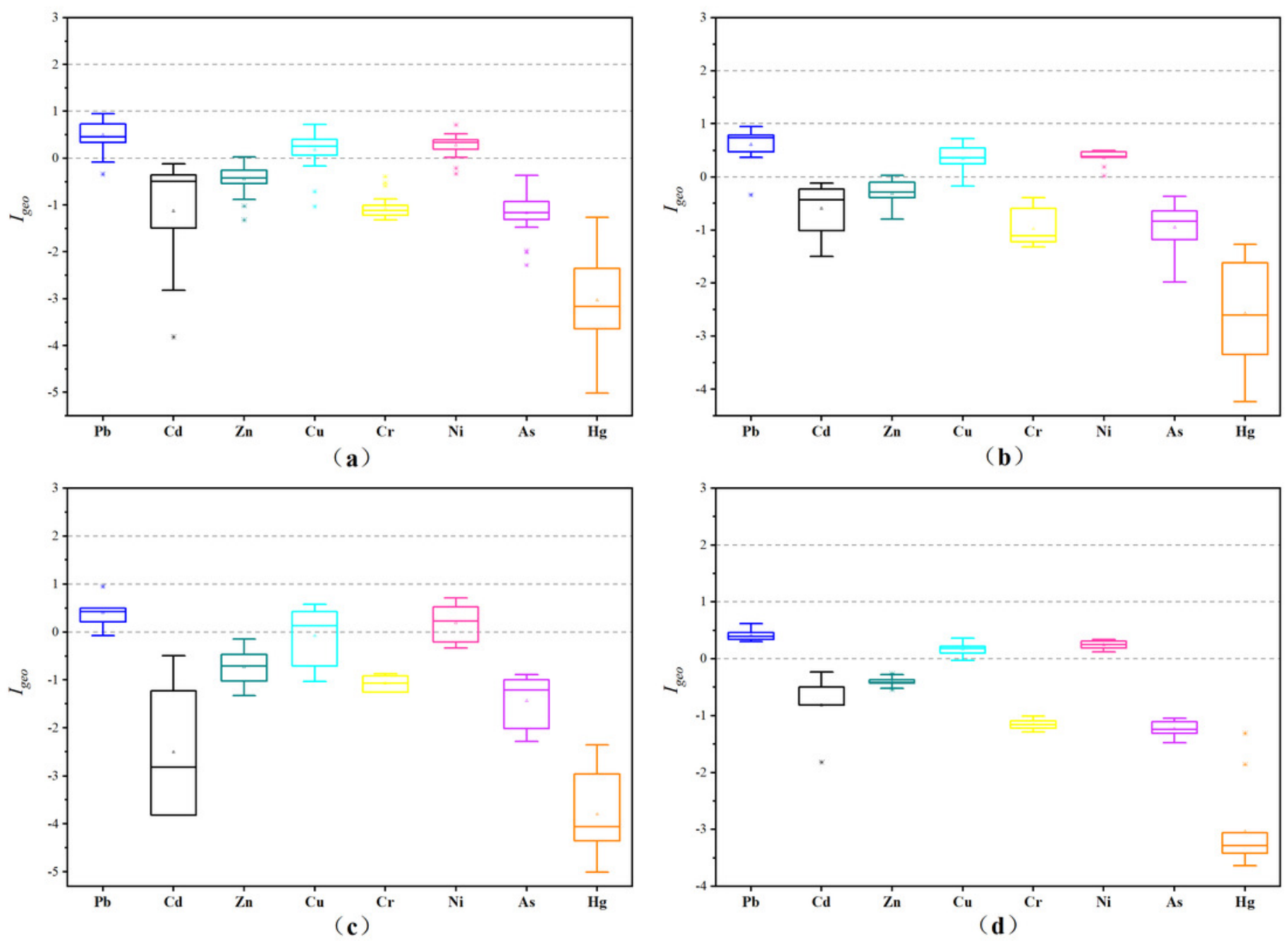
Figure 5

The $E_{r}^{i}$ and $R /$ of different regions

(a) whole study area; (b) farmland; (c) ditch; (d) lake area
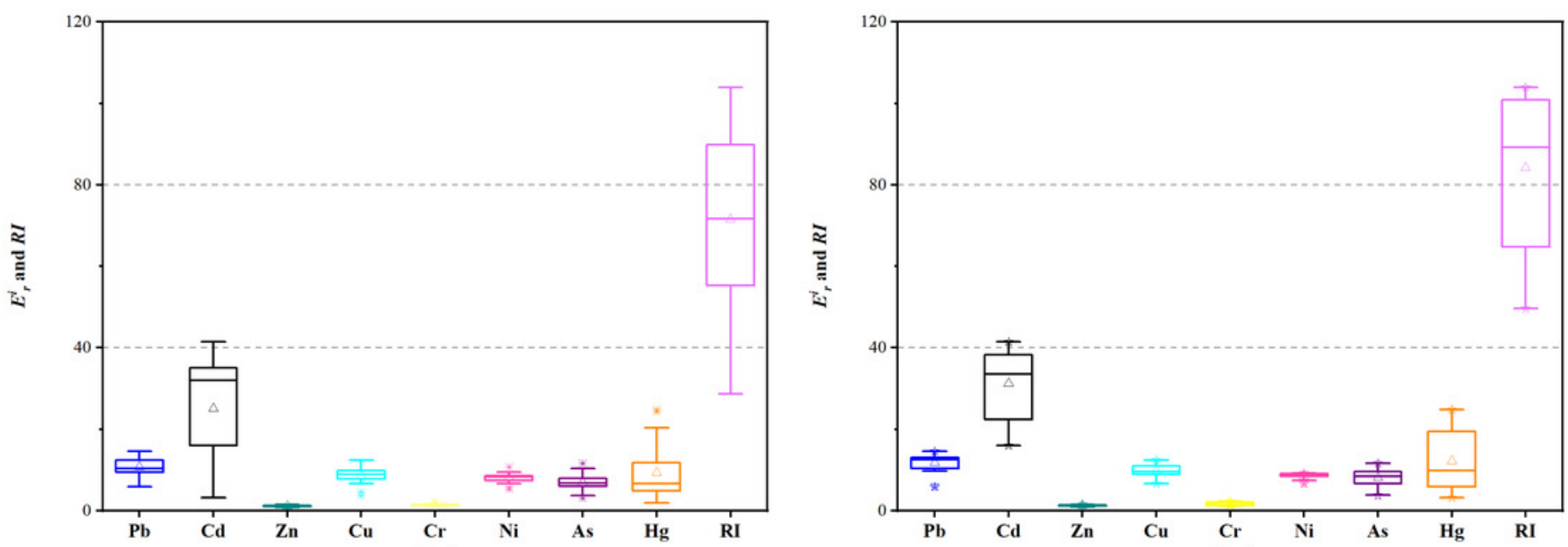

(a)
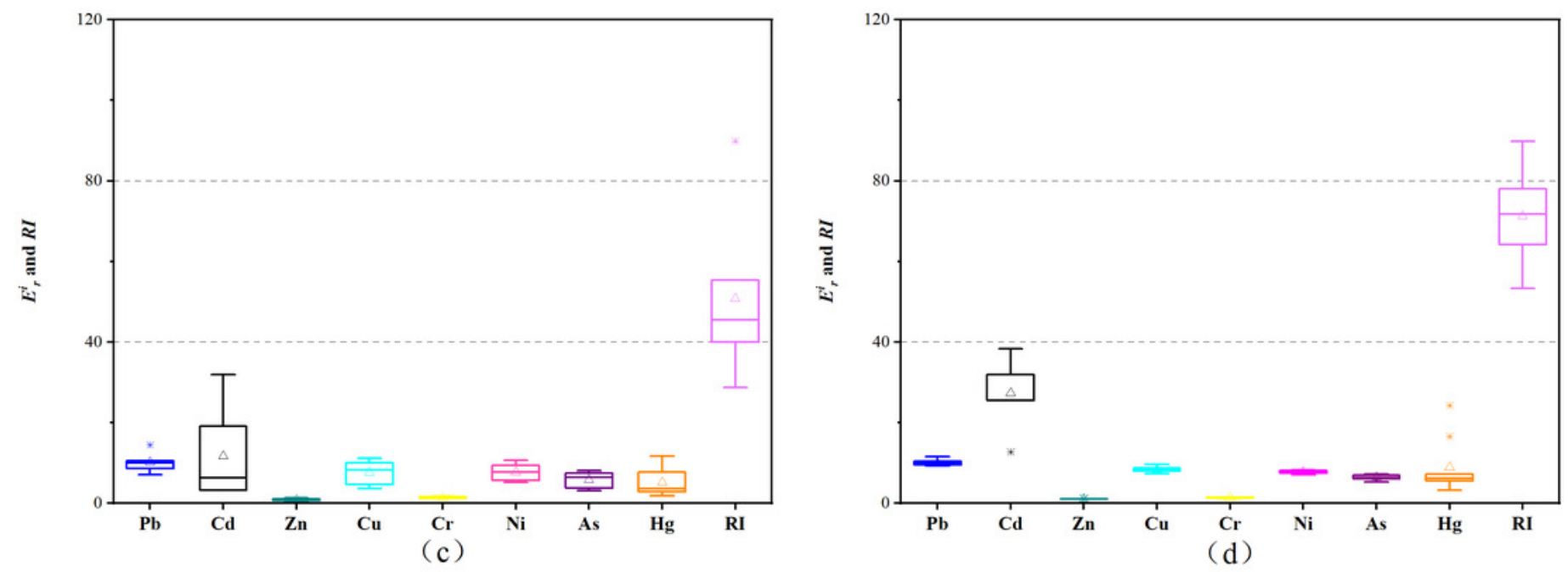
Figure 6

Heatmap of clustering heavy metals, As, and nutrients

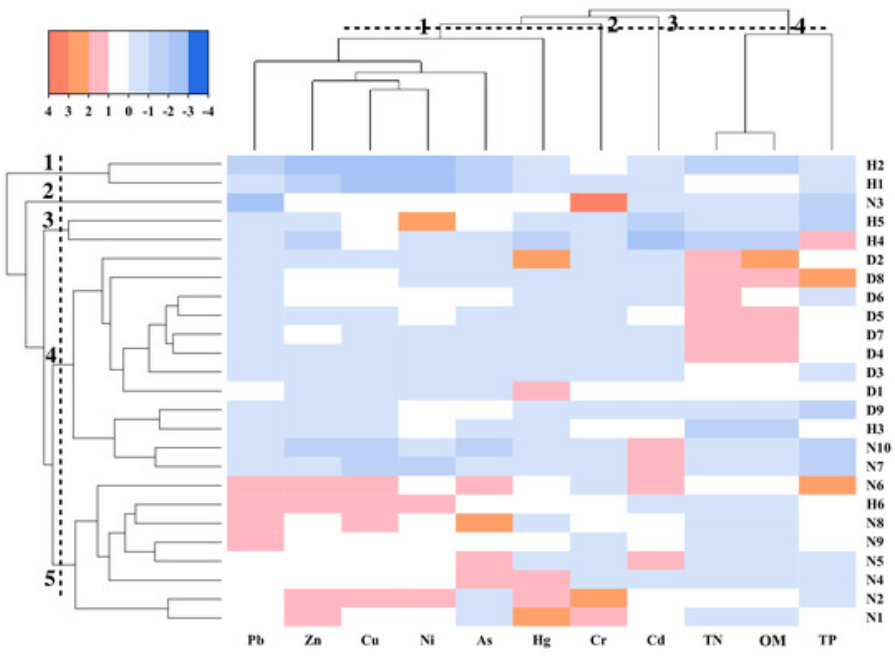


Figure 7

Loading plot of the principal component analysis

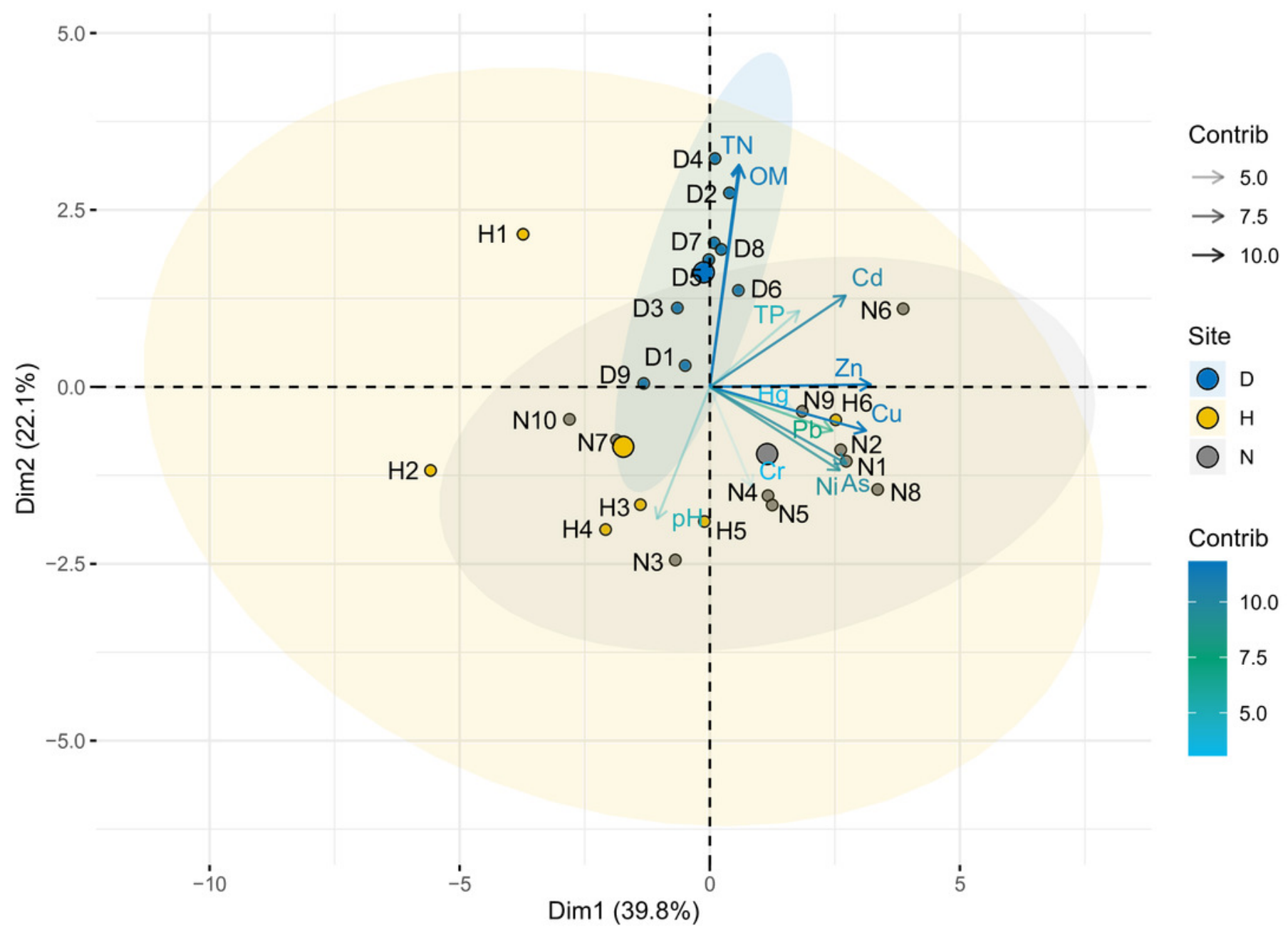


Table $\mathbf{1}$ (on next page)

Content of pollutants in different land-use types 
Table 1 Content of pollutants in different land-use types

\begin{tabular}{lcccc}
\hline & Background & \multicolumn{3}{c}{ Land type (mean \pm standard deviation) } \\
& values & Farmland $(\mathrm{n}=10)$ & Ditch $(\mathrm{n}=6)$ & Lake area $(\mathrm{n}=9)$ \\
\hline $\mathrm{Pb}(\mathrm{mg} / \mathrm{kg})$ & 21.5 & $49.25 \pm 9.94$ & $41.70 \pm 6.90$ & $42.98 \pm 3.14$ \\
$\mathrm{Cd}(\mathrm{mg} / \mathrm{kg})$ & 0.094 & $0.10 \pm 0.03$ & $0.04 \pm 0.04$ & $0.09 \pm 0.03$ \\
$\mathrm{Zn}(\mathrm{mg} / \mathrm{kg})$ & 78.4 & $96.20 \pm 16.44$ & $73.50 \pm 21.34$ & $88.78 \pm 5.83$ \\
$\mathrm{Cu}(\mathrm{mg} / \mathrm{kg})$ & 21.8 & $42.20 \pm 8.68$ & $33.50 \pm 13.29$ & $36.78 \pm 3.11$ \\
$\mathrm{Cr}(\mathrm{mg} / \mathrm{kg})$ & 68.3 & $53.50 \pm 13.54$ & $49.00 \pm 5.55$ & $46.11 \pm 2.71$ \\
$\mathrm{Ni}(\mathrm{mg} / \mathrm{kg})$ & 30.8 & $52.00 \pm 4.99$ & $47.67 \pm 13.22$ & $47.89 \pm 2.57$ \\
$\mathrm{As}(\mathrm{mg} / \mathrm{kg})$ & 13.6 & $11.04 \pm 3.17$ & $8.02 \pm 2.78$ & $8.74 \pm 0.84$ \\
$\mathrm{Hg}(\mathrm{mg} / \mathrm{kg})$ & 0.15 & $0.06 \pm 0.03$ & $0.02 \pm 0.01$ & $0.03 \pm 0.03$ \\
$\mathrm{TN}(\mathrm{g} / \mathrm{kg})$ & - & $1.97 \pm 0.48$ & $1.60 \pm 0.91$ & $3.92 \pm 0.69$ \\
$\mathrm{TP}(\mathrm{g} / \mathrm{kg})$ & - & $0.89 \pm 0.19$ & $0.91 \pm 0.17$ & $0.93 \pm 0.10$ \\
$\mathrm{OM}(\mathrm{g} / \mathrm{kg})$ & - & $30.86 \pm 8.45$ & $23.48 \pm 13.72$ & $60.61 \pm 8.91$ \\
\hline
\end{tabular}

2 